\title{
IMPACT OF SPONTANEOUS BREATHING TRIAL USING T-TUBE COMPARED TO PRESSURE SUPPORT VENTILATION ON RESPIRATORY FUNCTIONAL PARAMETERS IN CRITICALLY ILL PATIENTS
}

\author{
Amal Mohamed Abdel-Latif ${ }^{1}$, Dalia Abdel-Latif Abdel-Rahman ${ }^{2}$, Mohamed Hassan \\ Elanani $^{3}$ \\ 1 Faculty of Medicine, Zagazig University, Department of Pediatrics and Pediatric Cardiology, \\ Sharkia, Egypt \\ 2 Faculty of Medicine, Zagazig University, Department of Pediatrics, Sharkia, Egypt \\ 3 Faculty of Medicine, Zagazig University Hospitals, Department of Pediatrics Sharkia, Egypt
}

\begin{abstract}
Introduction: Spontaneous breathing with a conventional T-tube (TT) connected to the endotracheal tube has been frequently used in weaning from mechanical ventilation (MV), when compared with pressure support ventilation (PSV). However, the acute effects of spontaneous breathing using TT versus PSV on respiratory functional parameters $(\mathrm{PaCO} 2$ and $\mathrm{SaO} 2)$ have not been fully demonstrated.

Objective: The purpose of this study was to examine the effects of weaning using spontaneous breathing in TT compared to PSV on respiratory functional parameters in critically ill patients.

Method: Twenty-six patients who had received MV for more than $48 \mathrm{~h}$ and met the inclusion criteria for weaning were assessed. The patients were randomized into 2 groups. first group weaned using TT and second weaned using PSV. Respiratory functional parameters included pressure of carbon diaxoide (PaCO2), peripheral oxygen saturation $(\mathrm{SpO} 2)$ were measured.

Results: PSV mode had statistically significantly lower $\mathrm{PaCO} 2$ than TT mode during weaning $(\mathrm{P}<0.001)$. Also, PSV mode had statistically significantly higher $\mathrm{SaO} 2$ than TT mode during weaning $(\mathrm{P}=0.007)$.

Conclusion: PSV improves oxygenation and ventilation of patients during weaning from mechanical ventilation.

Key words:

Pediatric intensive care unit - mechanical ventilation

Corresponding author:Mohamed Hassan Ali Elanani

Tel: 01066076587

Email: $\underline{\text { m elanani@yahoo.com }}$
\end{abstract}

\section{INTRODUCTION}

M echanical ventilation (MV) is considered an important treatment option in the intensive care unit (ICU), although the duration of mechanical ventilation should be minimized. ${ }^{[1]}$

Weaning is used to describe the gradual process of decreasing ventilator support. It is estimated that $40 \%$ of the duration of mechanical ventilation is dedicated to the process of weaning. Delayed weaning can lead to complications such as ventilator induced lung injury, ventilator associated pneumonia and diaphragmatic dysfunction. On the other hand, early weaning can lead to complications like upper airway injury, defective gas

T-Tube is a well-established method that involves attaching the end of the endotracheal exchange, aspiration and respiratory muscle fatigue. $^{[2]}$

Spontaneous breathing trial (SBT) assesses the patient's ability to breathe while receiving minimal or no ventilator support. Patients weaned on T-tube have increased ventilatory demand ${ }^{[3]}$

In SBT, the patient will not receive any assisted ventilation, and patients are connected to the mechanical ventilation or T-piece with specified FIO2, and the tidal volume and respiratory rate depends on the patient's efforts. The ventilator monitors all the inspiratory and expiratory tidal volumes, respiratory rate, airway pressure, FIO2 and respiratory system compliance and alarms any changes in the patient's condition especially apnea. ${ }^{[4]}$

tube to a short piece of tubing that acts as a reservoir and a connection to the humidified 
fresh gas flow. Many clinicians use this method because it is simple, well tested, and imposes a pulmonary workload that is comparable to that encountered after extubation. There were initial concerns that the increased resistance to airflow and the increased work of breathing induced by the endotracheal tube resulted in a workload in excess of that required when the tube was removed. These studies, though, did not account for the airway inflammation and edema that frequently accompanies extubation, which results in little difference between the preextubation and postextubation workload. ${ }^{[5]}$

PSV is a flow-cycled but time-limited mode that supports each spontaneous breath and may be used in newborn infants as a stand-alone technique when reliable respiratory drive is present. Also, Pressure support ventilation is patient-triggered, in that the inspiratory time, respiratory rate and the minute ventilation remains under the control of the patient, thereby facilitating a natural pattern of breathing. Pressure support ventilation (PSV) is a spontaneous mode of ventilation. The patient initiates every breath and the ventilator delivers support with the preset pressure value. With support from the ventilator, the patient also regulates his own respiratory rate and tidal volume. ${ }^{[3]}$

\section{MATERIAL AND METHODS Patients and study design}

We screened patients with respiratory failure receiving $\mathrm{MV}$ for more than $48 \mathrm{~h}$, who had been admitted to the PICU and met the criteria for weaning from MV traditionally used in the PICU that included improvement or resolution of the cause of respiratory failure: adequate gas exchange indicated by $\mathrm{PaO} 2 / \mathrm{FiO} 2 \geq 200$ or $\mathrm{PaO} 2>60 \mathrm{mmHg}, \mathrm{SpO} 2 \geq 90 \%$ at a $\mathrm{FiO} 2 \leq 0.40$, with a PEEP $\leq 5 \mathrm{cmH} 2 \mathrm{O}$; Glasgow Coma Scale $\geq 11$; body temperature $\leq 38 \mathrm{C}$; hemoglobin level $>10 \mathrm{~g} / \mathrm{dl}$;physiological measurements of respiratory rate $(\mathrm{RR}) \leq 35 \mathrm{bpm}$, tidal volume $(\mathrm{VT})$ in spontaneous breathing $>5 \mathrm{~mL} / \mathrm{kg}$, negative inspiratory force $\leq 20-25 \mathrm{cmH} 2 \mathrm{O}$; hemodynamic stability with no vasoactive drugs (dopamine, dobutamine or noradrenaline) and no sedative agents. ${ }^{[1]}$

Those patients with previous arterial hypotension (systolic BP $<100 \mathrm{mmHg}$ ), cardiac arrhythmias (higher than $10 \%$ of the non-sinusoidal heart beats during the weaning period), cardiac pacemaker insertion, severe neurological disease, barotrauma, presence of chest tube, and/or vasoactive/sedative drug use were excluded from the study. The study was registered in clinical trials.

\section{Weaning parameters:}

Before the beginning of the protocol, $\mathrm{ABG}$ was done and $\mathrm{SaO} 2$ was observed using pulse oximetry.

The decision for weaning or extubation was determined by the intensive care physician who was blinded to the study design.

\section{Study protocol:}

First, clinical characteristics, including age, gender, reason for hospital admission, patient's history, reason and duration of $\mathrm{MV}$, and weaning parameters were recorded.

During PSV technique, the patient breaths spontaneously, and at each respiratory cycle, the ventilator causes a prefixed positive pressure synchronized with the inspiratory effort of the patient. The pressure level is maintained until the ventilator detects a drop at the end of the patient's inspiratory flow. Patients were ventilated with pressure of 10 $\mathrm{cmH} 2 \mathrm{O}$ to maintain a tidal volume of approximately $8 \mathrm{~mL} / \mathrm{kg}$ with $5 \mathrm{cmH} 2 \mathrm{O}$ of PEEP, fraction of inspired oxygen concentration $(\mathrm{FiO} 2)$ set as $40 \%$, and pressure triggering sensitivity was set as $-2 \mathrm{cmH} 2 \mathrm{O}$ during 30 min. ${ }^{[6]}$

During TT trial, patients spontaneously breathed with oxygen flow of $5 \mathrm{~L} / \mathrm{min}$ during 30 min as described elsewhere.it consists of removing the patient from ventilator and leaving the patient to breath spontaneously on a T-tube connected to oxygen source. T-tube connects $\mathrm{O} 2$ source to an artificial airway (ETT and tracheostomy). During T-piece weaning, periods of ventilator support are alternated with 
spontaneous breathing. The goal is to progressively increase the time spent off the ventilator. Throughout protocol were continuously measured pressure of carbon dioxide $(\mathrm{PaCO} 2)$ and peripheral oxygen saturation ( $\mathrm{SpO} 2)$ by $\mathrm{ABG}$ and pulse oximetry.

Data analysis:

\section{STATISTICAL ANALYSIS}

Data were analyzed by Statistical Package of Social Science (SPSS), software version 24.0 (SPSS Inc., 2016).

Continuous data were presented as the Mean \pm SD if normally distributed or Median (Range) if not normally distributed. Normality was checked by Shapiro-Wilk Test.

Categorical data were presented by the count and percentage.

- Independent-samples t-test: is used to determine if a difference exists between the means of two independent groups on a continuous dependent variable.

- Mann-Whitney u test (nonparametric alternative to independent-samples t-test).

- The paired-samples t-test (dependent t-test): is used to compare the means between two related groups on the same continuous, dependent variable

- Wilcoxon Signed-Rank Test: (nonparametric alternative to paired t-test)

- The chi-squared test: is used to discover if there is a relationship between two categorical variables.

- Fisher's Exact Test: for (RXC) table. It is an alternative to chi-squared test when the expected cell count is less than 5 .

- Significance level:

$P$-value $<0.05$ indicates significant, $P<0.01$ indicates highly significant difference, $P<0.001$ indicates very highly significant difference while, $\quad P \geq 0.05$ indicates non-significant difference.

\section{RESULTS}

Twenty-six patients were selected to take part in this study. Table 1 describes clinical and functional characteristics of all patients included. The respiratory parameters measured during the sequence studied between the groups are shown in Table 2,3,4 and 5. TT mode resulted in an increased $\mathrm{PaCO} 2$ with reduction in $\mathrm{SpO} 2$.

Table (1): Baseline characteristics and demographic data of the studied patients.

\begin{tabular}{|c|c|c|c|c|}
\hline \multirow[t]{2}{*}{ Variables } & TT & PSV & \multirow{3}{*}{$\begin{array}{c}\text { Significance } \\
\text { test }\end{array}$} & \multirow[t]{3}{*}{$P$-value } \\
\hline & $n=13$ & $n=13$ & & \\
\hline & Median (Range) & Median (Range) & & \\
\hline $\begin{array}{c}\text { Age } \\
\text { (months) }\end{array}$ & $\begin{array}{c}48 \\
(2-180)\end{array}$ & $\begin{array}{c}18 \\
(3-180)\end{array}$ & $\mathrm{MW}=76.5$ & 0.69 \\
\hline $\begin{array}{l}\text { Body Weight } \\
(\mathrm{Kg})\end{array}$ & $\begin{array}{c}15 \\
(3-60)\end{array}$ & $\begin{array}{c}9 \\
(4-53)\end{array}$ & $\mathrm{MW}=75.5$ & 0.65 \\
\hline Sex, & $N(\%)$ & $N(\%)$ & $\chi^{2}=0.65$ & 0.69 \\
\hline Males & $7(58 \%)$ & $9(69 \%)$ & & \\
\hline Females & $6(42 \%)$ & $4(31 \%)$ & & \\
\hline & Median (Range) & Median (Range) & $M W=58.5$ & 0.19 \\
\hline Duration of MV (days) & $\begin{array}{c}14 \\
(3-28) \\
\end{array}$ & $\begin{array}{c}5 \\
(2-120) \\
\end{array}$ & & \\
\hline Reason For MV & $N(\%)$ & $N(\%)$ & $\chi^{2}=0.16$ & 0.69 \\
\hline $\begin{array}{l}\text { Respiratory } \\
\text { Failure }\end{array}$ & $5(38 \%)$ & $6(46 \%)$ & & \\
\hline Others & $8(62 \%)$ & $7(54 \%)$ & & \\
\hline Comorbidity & $N(\%)$ & $N(\%)$ & Fisher's & $>0.99$ \\
\hline No & $4(30 \%)$ & $3(23 \%)$ & Exact Test & \\
\hline Yes & $9(70 \%)$ & $10(77 \%)$ & & \\
\hline
\end{tabular}

Table (1) shows that there are nonsignificant differences in baseline characteristics in TT mode $v s$ PSV mode patients $(P>0.05)$. 
Table (2): Comparison between TT weaning before and during weaning as regards $\mathrm{PaCO} 2$ and $\mathrm{SaO2}$.

\begin{tabular}{|c|c|c|c|c|}
\hline Variables & $\begin{array}{c}\begin{array}{c}\text { Before TT } \\
\text { weaning }\end{array} \\
(\mathrm{n}=13) \\
\end{array}$ & $\begin{array}{c}\begin{array}{c}\text { During TT } \\
\text { weaning }\end{array} \\
(\mathbf{n}=13) \\
\end{array}$ & $\begin{array}{c}\text { Paired sample-t } \\
\text { test }\end{array}$ & $P$-value \\
\hline & Mean \pm SD & Mean \pm SD & & \\
\hline PaCO2 & $40.9 \pm 13.9$ & $44.8 \pm 7.7$ & $t=0.94$ & 0.36 \\
\hline $\mathrm{SaO2}$ & $95.9 \pm 2.3$ & $93.4 \pm 2.5$ & $\mathrm{t}=4.1$ & 0.001 \\
\hline
\end{tabular}

Table (2) shows that PaCO2 didn't significantly alter before weaning from TT mode and during weaning $(P=0.36)$. TT mode had statistically significantly greater $\mathrm{SaO} 2$ before weaning than during weaning $(P=0.001)$.

Table (3): Respiratory parameters (ventilation, oxygenation) in patients before weaning from PSV mode and during weaning.

\begin{tabular}{|c|c|c|c|c|}
\hline Variables & $\begin{array}{c}\begin{array}{c}\text { Before PSV } \\
\text { weaning }\end{array} \\
(n=13)\end{array}$ & $\begin{array}{c}\text { During PSV } \\
\text { Weaning } \\
(n=13)\end{array}$ & Significance test & $P$-value \\
\hline & Mean \pm SD & Mean \pm SD & \multirow{2}{*}{$\begin{array}{l}\text { Paired sample-t } \\
\text { test }=4.6\end{array}$} & \multirow[t]{2}{*}{0.001} \\
\hline PCO2 & $41.5 \pm 8.8$ & $32.9 \pm 5$ & & \\
\hline & Median (Range) & Median (Range) & \multirow{2}{*}{$\begin{array}{c}\text { Wilcoxon } \\
\text { Signed rank test }= \\
40.5\end{array}$} & \multirow[t]{2}{*}{0.5} \\
\hline $\mathrm{SaO2}$ & $97(90-99)$ & $97(91-99)$ & & \\
\hline
\end{tabular}

Table (3) shows that PCO2 significantly decreased during weaning compared with before weaning $(\mathrm{P}=0.001)$, also there is nonsignificant difference in $\mathrm{SaO} 2$ in patients before weaning from $\mathrm{PSV}$ mode and during weaning was found $(\mathrm{P}=0.5)$.

Table (4): Respiratory parameters (ventilation, oxygenation) before weaning from TT mode and from PSV mode in the studied patients.

\begin{tabular}{|c|c|c|c|c|}
\hline & $\begin{array}{c}\text { TT } \\
(\mathbf{n}=13)\end{array}$ & $\begin{array}{c}\text { PSV } \\
(n=13)\end{array}$ & Significance test & P-value \\
\hline Variables & $\begin{array}{l}\text { Median } \\
\text { (Range) }\end{array}$ & Median (Range) & \multirow{2}{*}{$\begin{array}{l}\text { Mann-Whitney u } \\
\text { test }=103.5\end{array}$} & \multirow[t]{2}{*}{0.34} \\
\hline $\mathrm{PCO} 2$ & $37(28-83)$ & $40(25-55)$ & & \\
\hline & $\begin{array}{l}\text { Median } \\
\text { (Range) }\end{array}$ & Median (Range) & $\begin{array}{c}\text { Mann-Whitney u test } \\
=90.5\end{array}$ & 0.76 \\
\hline
\end{tabular}

Table (4) shows that there are nonsignificant differences in respiratory parameters in patients in TT mode compared with PSV mode before weaning $(\mathrm{P}>0.05)$. 
Table (5): Respiratory parameters (ventilation, oxygenation) during weaning from TT mode and from PSV mode in the studied patients.

\begin{tabular}{cccccc}
\hline \multirow{2}{*}{ Variables } & TT & PSV & Significance test & \multirow{2}{*}{ P-value } \\
\cline { 2 - 3 } & $\begin{array}{c}(\mathbf{n}=\mathbf{1 3}) \\
\text { Mean } \pm \text { SD }\end{array}$ & $\begin{array}{c}\text { Mean } \pm \text { SD } \\
\text { PCO2 }\end{array}$ & $\begin{array}{c}\text { Independent sample-t } \\
\text { test }=4.7\end{array}$ & $<\mathbf{0 . 0 0 1}$ \\
\hline SaO2 & $94.8 \pm 7.7$ & $32.9 \pm 5$ & & $\begin{array}{c}\text { Independent sample-t } \\
\text { test }=2.9\end{array}$ & $\mathbf{0 . 0 0 7}$ \\
\hline
\end{tabular}

Table (5) shows that PSV mode had statistically significantly lower PCO2 than TT mode during weaning $(\mathrm{P}<0.001)$. Also, PSV mode had statistically significantly higher $\mathrm{SaO} 2$ than TT mode during weaning $(\mathrm{P}=0.007)$.

\section{DISCUSSION}

This study was carried on children with critical illnesses who were admitted to pediatric intensive care unit (PICU) in Zagazig University Hospitals during 2017/2018 and connected to mechanical ventilation for more than $48 \mathrm{~h}$ and met the criteria for weaning from MV. It included 26 critically ill children, divided into 2 groups (13) in each one, first group included children weaned from mechanical ventilation using T-tube and second group included children weaned using pressure support ventilation.

This study evaluated the effects of TT and PSV weaning modes on respiratory functional parameters in critically ill patients underwent to weaning from MV.

The aim of this study was to assess the parameters of gas exchange and respiratory mechanics during weaning from mechanical ventilation using spontaneous breathing in TT compared to PSV in critically ill patients.

For achieving these purposes, 2 groups of 26 children were studied. as regarded demographic data of studied patients, it was found that in group (A) patients 7 of them were males (58\%), 6 were females $(42 \%)$ with mean age $48 \mathrm{~m}$ ( range 2 to $180 \mathrm{~m}$ ) mean weight was $15 \mathrm{~kg}$ (range 3 to $60 \mathrm{~kg}$ ) but in group (b) patients 9 of them were males $(69 \%), 4$ were females $(31 \%)$ with mean age $18 \mathrm{~m}$ (range 3 to $180 \mathrm{~m}$ ) $9 \mathrm{~kg}$ (range 4 to $53 \mathrm{~kg})$. We found that there were no statistical significant differences between 2 studied groups as regarding age and sex and weight.

In our study, regarding duration of mechanical ventilation there were no significant differences between 2 groups with mean duration of $\mathrm{MV}$ was $14 \mathrm{~d}$ (range 3 to 28 ) in $\mathrm{T}$ tube compared with 5d (range 2 to 120) in PSV. These results were in agreement with Vitacca et al., (2001) that reported that there was insignificant difference in mean duration of $\mathrm{MV}$ between patients weaned using T-tube and PSV, but these results were conflicted with Matić (2004) that reported median values for PS versus T-tube were 215 (range 187 to 259) and 262 hours (range 216 to 328) respectively, thus significantly favouring the PS group $(\mathrm{P}<0.001)$, also Matić (2007) reported median values favouring the PS group (163, range 113 to 203) compared with the T-tube group (187, range 143 to 328$)(\mathrm{P}<0.001){ }^{[7]}$

As regarding respiratory parameters in our study, PCO2 didn't significantly altered before weaning from TT mode and during weaning $(P=0.36)$. TT mode had statistically significantly greater $\mathrm{SaO} 2$ before weaning than during weaning $(P=0.001)$, but during PSV weaning, PCO2 significantly decreased during weaning compared with before weaning $(P=0.001)$ and $\mathrm{SaO} 2$ didn't significantly altered before weaning from PSV mode and during weaning $(P=0.5)$, but there were no significant differences in respiratory parameters in patients in TT mode compared with PSV mode before weaning $(P>0.05)$.

In our study, PSV mode had statistically significantly lower PCO2 than TT mode during 
weaning $(P<0.001)$. Also, PSV mode had statistically significantly higher $\mathrm{SaO} 2$ than TT mode during weaning $(P=0.007))$. This agreed with Costa et al., 2005 that detected that the total $\mathrm{SaO} 2$ values were significantly more elevated during pressure support, but this was in contrast with Chiappa et al., (2017) ${ }^{[8]}$ that detected that $\mathrm{SpO} 2$ values was maintenance in both weaning modalities (Koelwyn et al., 2013), and supported by Manjush et al., (2014) who compared three weaning modes namely (PSV, CPAP, and T-piece). They concluded that there was no difference between the three weaning modes as regards $\mathrm{ABG}$, and that the three modes were comparable as regards $\mathrm{PO} 2, \mathrm{PCO} 2, \mathrm{PH}(\mathrm{P}$ value $>0.05){ }^{[9]}$

Jubran and Tobin (1997) have shown that the patients who fail the weaning trials develop rapid and superficial breathing, which, along with the mechanical overload, leads to the deficient elimination of carbon dioxide, resulting in hypoventilation and ineffective gas exchange. According to the same mechanism, one may infer that an increase in the minute volume may improve $\mathrm{CO} 2$ elimination. ${ }^{[10]}$

Chatila et al., (1996) reported that patients who failed to wean from mechanical ventilation (using a $\mathrm{T}$ tube), had drop in oxygen saturation, showing that oxygen desaturation may be rather due to failure to wean than be its cause. ${ }^{[11]}$

Chiappa et al., (2017) found that there was significant increase in $\mathrm{PaCO} 2$ during $\mathrm{TT}$, which may be associated with higher ventilator inefficiency and may stimulate chemoreceptors in the brainstem affecting HRV spectrum. There is evidence that arterial $\mathrm{CO} 2$ is able to modulate heart rate variability by decreasing the firing rate of the autonomic nervous system.

\section{CONCLUSION}

PSV improves oxygenation and ventilation of patients during weaning from mechanical ventilation.

REFERENCES

1. Costa AD, Rieder Mde $M$ and Vieira SR. Weaning from mechanical ventilation using pressure support or T-tube ventilation. Comparison between patients with and without heart disease. Arq Bras Cardiol. 2005; 85: 328.

2. MacIntyre NR. The ventilator discontinuation process: an expanding evidence base. Respiratory care. 2013;58(6):1074-86.

3. Bonett S, Banner MJ, Euliano NR, et al. "Pressure support ventilation advisory system provides valid recommendations for setting ventilator". Respir Care. 2011;56 (3): 271-7.

4. Talwar D and Dogra V. Weaning from mechanical ventilation in chronic obstructive pulmonary disease: Keys to success. J Assoc Chest Physicians. 2016;4(2):43-9.

5. Mehta $S$ and Hill NS. Noninvasive ventilation, state of art. Am J Respir Crit Care Med. 2001; 163:540-77.

6. Papaioannou VE, Chouvarda I, Maglaveras N, et al. Changes of heart and respiratory rate dynamics during weaning from mechanical ventilation: a study of physiologic complexity in surgical critically ill patients. J Crit Care. 2011; 26: 262-72.

7. Vitacca M, Vianello A, Colombo D, et al. Comparison of two methods for weaning patients with chronic obstructive pulmonary disease requiring mechanical ventilation for more than 15 days. Am J Respir Crit Care Med. 2001; 164: 225 230.

8. Chiappa AMG, Chiappa GR, Cipriano G, et al. Spontaneous breathing trial in T-tube negatively impact on autonomic modulation of heart rate compared with pressure support in critically ill patients. Clin Respir J. 2017; 11: 489-495.

9. Manjush, Sammita J. Jadhav, et al. An evaluation of weaning trials in relation with mean arterial pressure, respiratory rate, arterial blood gases and successful extubation, World J. Med. Sci. 2017;10(4):415-420.

10. Jubran A and Tobin M. Pathophysiologic basis of acute respiratory distress in patients who fail a trial of weaning from mechanical ventilation. Am J Respir Crit Care Med. 1997; 155:906-15.

11. Chatila W, Ani S, Guaglianone D, et al. Cardiac ischemia during weaning from mechanical ventilation. Chest. 1996;109: 1421-9. 